\title{
Article
}

\section{Evaluation of Nitrate as Internal Standard for Quantitative Determination of Urea in Urine by Raman Spectroscopy}

\author{
Felipe Manfroi Fortunato", Marcos André Bechlin¹, Edilene Cristina Ferreira', Silvana Ruella Oliveira² \\ and José Anchieta Gomes Neto ${ }^{1 *}$ \\ ${ }^{1}$ São Paulo State University - UNESP, Analytical Chemistry Department, Rua Prof. Francisco Degni 55, \\ CEP 14800-060, Araraquara, SP, Brazil \\ ${ }^{2}$ University of São Paulo - USP, Faculty of Pharmaceutical Sciences of Ribeirão Preto - FCFRP \\ Avenida do Café s/n, CEP 14040-903, Ribeirão Preto, SP, Brazil
}

\section{Graphical Abstract}

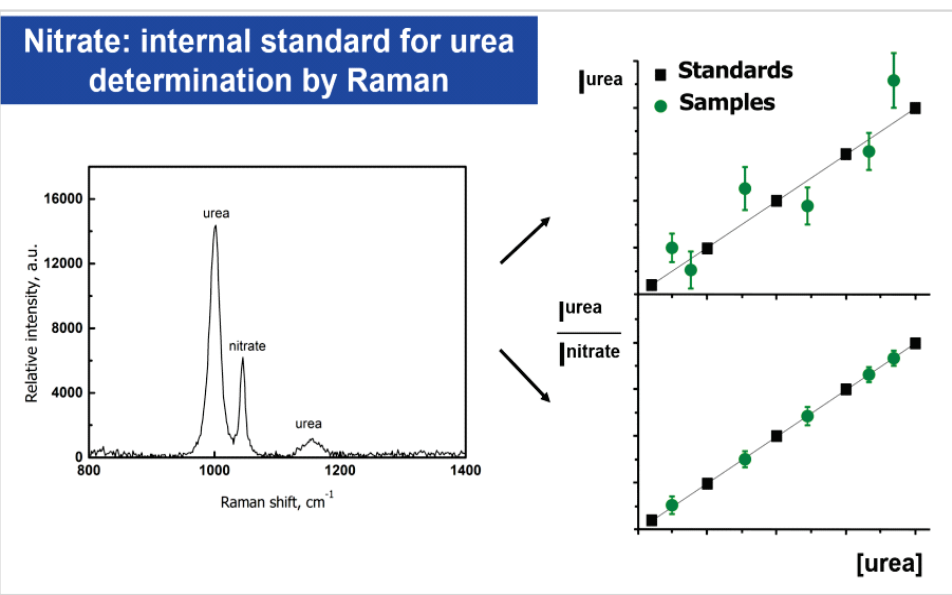

Nitrate was tested as internal standard in a new method for urea determination in urine by Raman spectroscopy. The proposed method furnished better precision in comparison with conventional methods. Besides, it is simple, robust and provides faster results, minimum sample preparation and lower reagent consumption and minimum waste generated than the reference spectrophotometric method.

Nitrate was evaluated as internal standard (IS) for urea determination in urine by Raman spectroscopy. The influence of main operating parameters (laser power and integration time) on the Raman scattering of urea (N-C-N stretching at $1003 \mathrm{~cm}^{-1}$ ) and nitrate (N-O stretching at $\left.1045 \mathrm{~cm}^{-1}\right)$ was evaluated and the results showed good correlation between analyte and IS signals. The method was then developed and applied in five urine samples which presented urea concentrations in the $7.3-18.3 \mathrm{~g} \mathrm{~L}^{-1}$ range. For comparative purposes, samples were also analyzed by the reference method based on the enzymatic hydrolysis of urea followed by the spectrophotometric determination of ammonium ions. Results obtained by the proposed IS method were in agreement with the reference method at the $95 \%$ confidence level (paired $t$-test). Relative standard deviations $(n=12)$ of a sample analyzed by the reference method, proposed IS method and conventional external calibration method were in the ranges of $3.8-6.3 \%, 1.4$ $3.9 \%$ (IS) and $1.8-7.5 \%$, respectively. Recoveries improved from $85-108 \%$ to $97 \%-103 \%$ intervals when samples were analyzed by the conventional external calibration and IS proposed method, respectively.

Keywords: Urea; urine; nitrate; internal standard; Raman spectroscopy.

\section{INTRODUCTION}

Analysis of biological fluids provides information about the health of a patient $[1,2]$. For example, the urea contents in blood or urine furnish an indicative for hepatic and kidney diseases diagnosis [3]. The normal levels of urea concentration in blood and urine are in the $0.15-0.4 \mathrm{~g} \mathrm{~L}^{-1}$ and $9.3-23.3 \mathrm{~g} \mathrm{~L}^{-1}$ ranges, respectively [4]. That determination is commonly carried out by the enzymatic hydrolysis of urea to produce ammonium ions, which are quantified by spectrophotometric methods based on Berthelot [5] and Nessler 
[6] reactions. However, these spectrophotometric methods require sample pretreatments and consume a large amount of reagents, which generates substantial amounts of residues and are time-consuming.

Therefore, some electrochemical $[7,8]$ and chromatographic $[9,10]$ methods were proposed as alternatives. The electrochemical methods are based on the use of selective electrodes or biosensors with immobilized enzymes on the electrode surface [7,8]. Despite the low cost of these methods, they require rigid temperature and $\mathrm{pH}$ control, and are deeply susceptible to matrix interferences. Regarding chromatographic methods, clean up steps (sample pretreatments) are usually required. Furthermore, the high costs for equipment acquisition and maintenance restrict their use in small laboratories.

Hence, the development of alternative methods of quantitative analysis that operate in adherence to the principles of Green Chemistry is attractive [11]. In this sense, laser-based techniques have showed potential for using in assorted chemical analyses [12]. The Raman vibrational spectroscopy [13] has been presented noteworthy advances in the last decades due to the possibility of direct and non-destructive sample analysis, instrumental simplicity, high analytical throughput and portability [14], and reduced interference caused by the sample fluorescence by using diode lasers $(780-830 \mathrm{~nm})$ [15]. Despite the technical improvements in Raman instrumentation in the last years, systematic and random errors are often observed and the choice of a proper calibration method is crucial to reduce/eliminate fluctuations caused by instrumental oscillations or matrix interferences [16].

The internal standardization calibration method is simple, fast, of easing construction and has been employed to minimize random/systematic errors [17]. The use of internal standard (IS) in Raman is reported in the literature with good results for different analytes (A) and samples (S). Among the main uses are (IS/A/S): 4-mercaptopyridine/3,4-methylenedioxymethamphetamine and a-methyltryptamine hydrochloride/drugs [18]; d-nicotine/nicotine/liquids for electronic cigarettes [19], amide/poly(3-hydroxybutyrate)/bacteria [20]; OH stretching band of water/sulfate/aqueous solution [21]; 1-propanethiol/polycyclic aromatic hydrocarbons/food contact materials [22]. However, the selection of a suitable IS for a specific problem is still a challenge.

Despite of potentialities of both Raman and internal standardization for analytical purposes, little attention has been given for the use of internal standardization for urine quantitative analysis. Also, the evaluation of nitrate as IS for quantitative determination of urea in urine is not found in the literature. Thus, the goal of this work is the development of a simple, fast and green method for urea determination in urine by Raman spectroscopy and the evaluation of nitrate as a possible IS.

\section{MATERIALS AND METHODS Instrumentation}

Raman spectra were obtained using a B\&W Tek iRaman BWS415-785H spectrometer with a $785 \mathrm{~nm}$ laser (power $<350 \mathrm{~mW}$ ) and $3.5 \mathrm{~cm}^{-1}$ spectral resolution. The excitation and acquisition spectra of blanks, standards and urine samples were carried out by means of an optical fiber coupled to a B\&W Tek BCR100A cuvette support.

All the Raman shifting spectra $(n=5)$ were obtained in the $150-2700 \mathrm{~cm}^{-1}$ range employing the following instrumental parameters: $50 \%$ of laser power and $20 \mathrm{~s}$ integration time. The background of all spectra was corrected by using the Background Removal tool from the software BWSpec (B\&W Tek).

A Bel Photonics UV-M51 spectrophotometer was used for urea determination by the reference method. All measurements were carried out at $700 \mathrm{~nm}$, and at temperate controlled of $37^{\circ} \mathrm{C}$ using a SOLAB SL $150 / 10$ thermostatic bath.

\section{Reagents, analytical solutions and samples}

High-purity deionized water obtained using a Millipore Rios $5^{\mathrm{TM}}$ reverse osmosis and a Millipore Milli- $\mathrm{Q}^{\mathrm{TM}}$ Academic $^{\circledR}$ deionizer system (resistivity $18.2 \mathrm{M} \Omega . \mathrm{cm}$ ) was used throughout for solutions preparation. 


\section{Article}

Fortunato, F. M.; Bechlin, M. A.; Ferreira, E. C.; Oliveira, S. R.; Neto, J. A. G.

A $100 \mathrm{~g} \mathrm{~L}^{-1}$ urea standard stock solution was prepared by dissolving $50 \mathrm{~g}$ of urea (Sigma Aldrich) in 500 $\mathrm{mL}$ of deionized water. Analytical solutions in the $100-700 \mathrm{mg} \mathrm{L}^{-1}$ interval were daily prepared by appropriate dilution of the stock solution. A $100 \mathrm{~g} \mathrm{~L}^{-1}$ nitrate standard stock solution was prepared by dissolving $67.2 \mathrm{~g}$ of $\mathrm{NaNO}_{3}$ (Merck) in $500 \mathrm{~mL}$ of deionized water.

The reference method for urea determination was carried out by using the commercial Labtest kit containing the following solutions: solution 1 (phosphate buffer $10 \mathrm{mmol} \mathrm{L}{ }^{-1}+$ urease: $\geq 268 \mathrm{kU} \mathrm{L}^{-1}$ ); solution 2 (phosphate buffer $100 \mathrm{mmol} \mathrm{L}^{-1}+\mathrm{C}_{7} \mathrm{H}_{5} \mathrm{O}_{3} \mathrm{Na} 312 \mathrm{mmol} \mathrm{L}{ }^{-1}+\mathrm{Na}_{2}\left[\mathrm{Fe}(\mathrm{CN})_{5} \mathrm{NO}\right] 16.8 \mathrm{mmol} \mathrm{L}^{-1}$ ); solution 3 $\left(\mathrm{NaOH} 2.8 \mathrm{~mol} \mathrm{~L}^{-1}+\mathrm{NaClO} 121 \mathrm{mmol} \mathrm{L}^{-1}\right)$; solution $4\left(700 \mathrm{mg} \mathrm{L}^{-1}\right.$ urea). These solutions were prepared and used according to the manufacturer instructions, as follow: $100 \mathrm{~mL}$ of solution $2+25 \mathrm{~mL}$ of solution 3 were diluted to $500 \mathrm{~mL}$ with deionized water; the solution 1 was mixed with the solution 2 and 20 -fold diluted.

All urine samples were analyzed by Raman spectroscopy without any previous sample preparation. For the reference method, samples were diluted 50 -fold with deionized water.

\section{Analytical procedure}

The behaviors of nitrate and urea were evaluated at different laser power and integration time conditions. Raman scattering of a solution containing $40 \mathrm{~g} \mathrm{~L}^{-1}$ urea $+10 \mathrm{~g} \mathrm{~L}^{-1}$ nitrate were measured fixing the integration time at $10 \mathrm{~s}$ and varying the laser power from 10 to $90 \%$ maximum power. Thereafter, the laser power was fixed at $50 \%$ (optimized condition) and the integration time varied from 1 to $40 \mathrm{~s}$.

The linear working ranges for nitrate and urea were evaluated in the $0.5 \mathrm{~g} \mathrm{~L}^{-1}-50 \mathrm{~g} \mathrm{~L}^{-1}$ intervals using $50 \%$ laser power and $20 \mathrm{~s}$ integration time.

Urea was determined in five urine samples employing the proposed IS method. All blanks, standard solutions and samples were spiked with $10 \mathrm{~g} \mathrm{~L}^{-1}$ of nitrate as internal standard. Raman scatterings (Relative intensities) of blanks, standard solutions and samples were measured in triplicate using operating parameters fixed at $50 \%$ of laser power and $20 \mathrm{~s}$ integration time. The calibration curve was built up by plotting on the $y$-axis scattering measurements of urea/scattering measurements of nitrate $\left(I_{\text {urea }} / I_{\text {nitrate }}\right)$ and on the $x$-axis the urea concentration. The contents of urea in samples were obtained by interpolation of measured scatterings of samples on that curve.

For comparative purposes, all samples were also analyzed by a spectrophotometric reference method and Raman spectroscopy with conventional external calibration ( $0-40 \mathrm{~g} \mathrm{~L}^{-1}$ of urea). For the reference method, measurements of blanks, standards and diluted samples were carried out according to the following steps: in a test tube, it was added $20 \mu \mathrm{L}$ of blanks, standards or diluted samples $+2 \mathrm{~mL}$ of the mixture 1:20 of solution 1 and solution 2 (buffered urease + salicylate + sodium nitroprusside) $+2 \mathrm{~mL}$ of the diluted solution $3(\mathrm{NaOH}+\mathrm{NaClO})$. After homogenizing, the tubes were immersed in a $37^{\circ} \mathrm{C}$ bath for 5 minutes, cooled and measured at $700 \mathrm{~nm}$.

Accuracy was also by means of addition and recovery tests for five urine samples spiked with $15 \mathrm{~g} \mathrm{~L}^{-1}$ of urea and analyzed by the proposed IS method and conventional external calibration.

\section{RESULTS AND DISCUSSION}

\section{Evaluation of nitrate as internal standard}

Urea is a nitrogen compound that presents the chemical formula $\left(\mathrm{NH}_{2}\right)_{2} \mathrm{CO}$ and a Raman spectrum with a characteristic intense peak at nearly $1003 \mathrm{~cm}^{-1}$ referring to the $\mathrm{N}-\mathrm{C}-\mathrm{N}$ stretching [17]. The nitrate $\left(\mathrm{NO}_{3}{ }^{-}\right)$ presents an intense peak at nearly $1045 \mathrm{~cm}^{-1}$ due to the $\mathrm{N}-\mathrm{O}$ stretching [23]. Shown in Figure 1 is the Raman spectrum of $50 \mathrm{~g} \mathrm{~L}^{-1}$ of urea and $5 \mathrm{~g} \mathrm{~L}^{-1}$ of nitrate using $20 \mathrm{~s}$ integration time and laser fixed at $50 \%$ of maximum power. Figure 1 shows that the nitrate and urea peaks are well resolved (do not occur overlaps) and appear in the same spectral region, which allows the simultaneous monitoring. These findings make nitrate a possible candidate as IS for urea determination. 


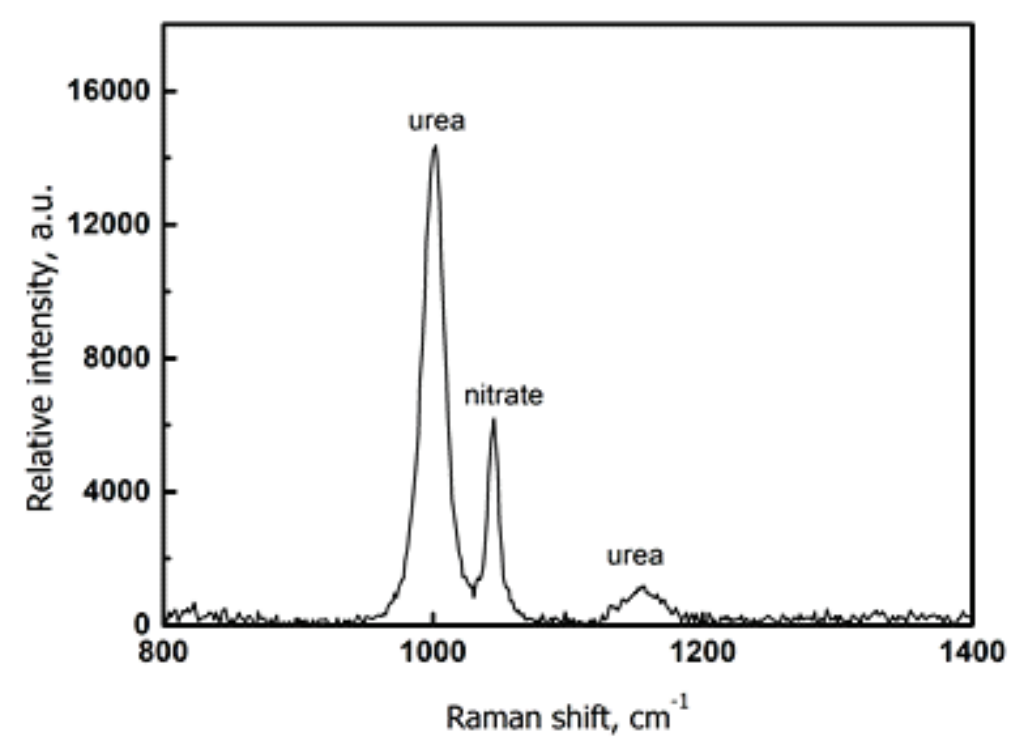

Figure 1. Raman spectrum of $50 \mathrm{~g} \mathrm{~L}^{-1}$ of urea and $5 \mathrm{~g} \mathrm{~L}^{-1}$ of nitrate using laser power fixed at $50 \%$ and integration time fixed at $20 \mathrm{~s}$.

Considering the requisite of internal standardization method by which the behavior of the IS should mimic that of the analyte, the performance of nitrate as IS for urea was evaluated by studying the behavior of nitrate and urea standards at different integration times and excitation conditions. First, Raman scattering of nitrate and urea were measured by fixing the integration time at $10 \mathrm{~s}$ and varying the laser power from 10 to $90 \%$ of maximum power. It was found an increase in the signals of both nitrate and urea with increasing laser power (Figure 2). This figure shows that both species presented similar behaviors since the ratio $\left(I_{\text {urea }} / I_{\text {nitrate }}\right)$ remains almost constant in the $20-90 \%$ laser power interval. Thereby, eventual fluctuations in the power laser during the measurements do not reflect in significant errors if the internal standardization is used.

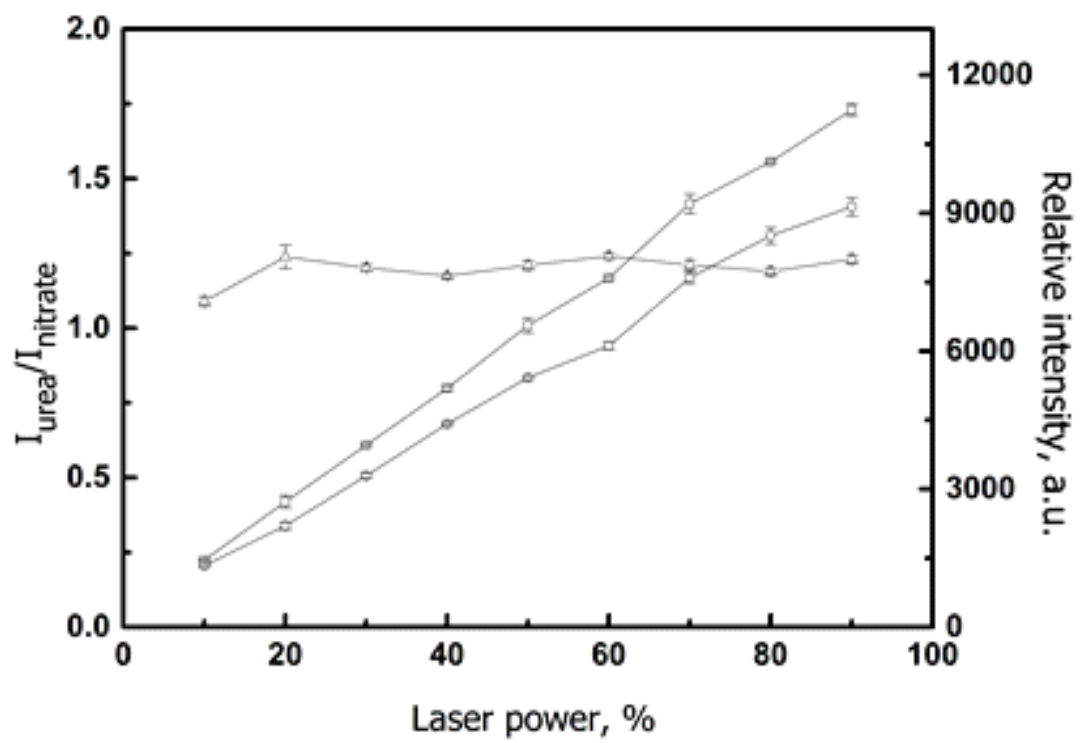

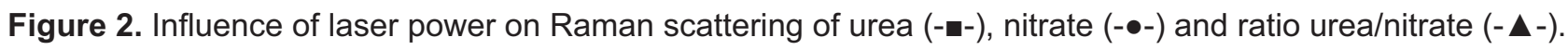

Signals obtained with integration time fixed at $10 \mathrm{~s}$. Relative intensity means the Raman scattering measurements. $I_{\text {urea }} / I_{\text {nitrate }}$ means the ratio scattering measurements of urea/scattering measurements of nitrate. 


\section{Article}

The behavior of the urea and nitrate was also evaluated by changing the integration time (1 - $40 \mathrm{~s})$ but fixing the laser power at $50 \%$ of the maximum. Figure 3 shows that signals of both urea and nitrate increased with increasing integration time. These findings show that nitrate and urea present similar behavior since the ratio $\left(\mathrm{I}_{\text {urea }} / \mathrm{I}_{\text {nitrate }}\right)$ remains almost constant in the monitored interval. Considering nitrate and urea showed similar behaviors through variations in the main instrumental conditions of Raman technique, the nitrate was considered a potential IS for urea determination in urine samples, so it was further evaluated in real samples.

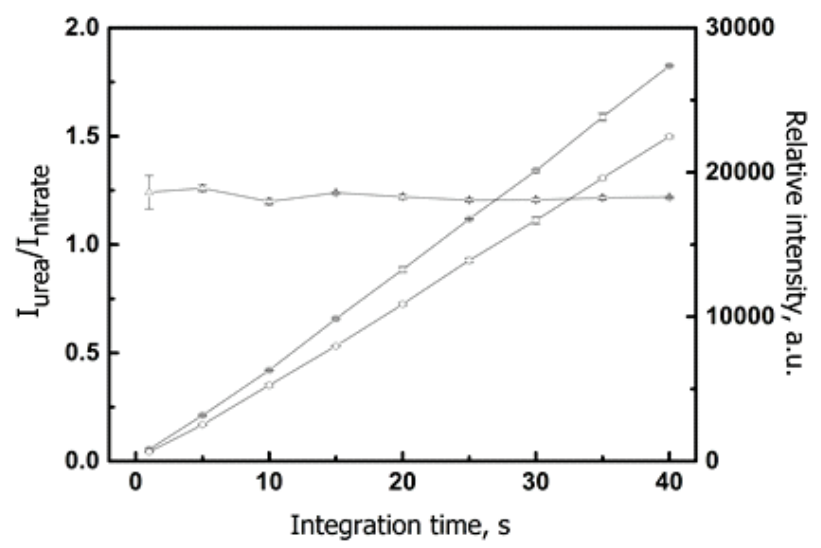

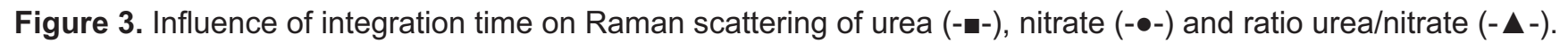

Signals obtained with laser power fixed at $50 \%$. Relative intensity means the Raman scattering

measurements. $I_{\text {urea }} / I_{\text {nitrate }}$ means the ratio scattering measurements of urea/ scattering measurements of nitrate.

\section{Optimization of the method}

The generation of intense background fluorescence for some workable samples and spectrometers may hinder the observation of the target Raman spectrum [24]. Preliminary tests carried out in urine samples showed noteworthy background fluorescence. Considering the signal is proportional to the power of the laser exciting the sample, the laser power was elected as $50 \%$ of maximum as a compromise between required sensitivity and sample preservation (possibility of burning when exposed to full laser power). When the integration time was evaluated $(10,15,20,25$ and $30 \mathrm{~s}$ ) in a urine sample, an increase in the Raman signal of urea and the shot noise (noise proportional to the intensity of the either Raman or fluorescence) was observed (Figure 4). Integration times $25 \mathrm{~s}$ resulted in lower signal-to-noise (SNR) ratios. Longer exposure time did not improve SNR. The shot noise caused by the fluorescence signal contributes more to the spectrum noise level than other sources of noise. So, the optimized parameters for further experiments were laser power at $50 \%$ of maximum and $20 \mathrm{~s}$ integration time.

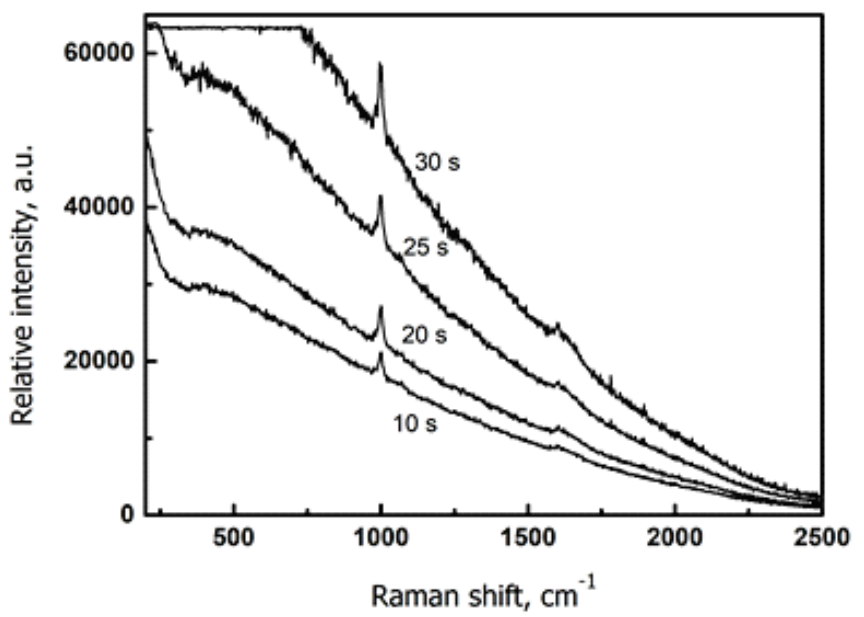

Figure 4. Influence of integration time $(10-30 \mathrm{~s})$ on Raman shift corresponding to an urine sample using laser power at $50 \%$ of maximum. 
Afterwards, the linear working ranges for nitrate and urea were evaluated by measuring the Raman scatterings for nitrate and urea standards. Curves with good correlation coefficients $(r \geq 0.9996)$ for nitrate and urea in the $0.5-50 \mathrm{~g} \mathrm{~L}^{-1}$ and $1-50 \mathrm{~g} \mathrm{~L}^{-1}$, respectively, were found. The concentration of a given candidate as IS should be within the limit of quantification and the upper limit of linear response, and the optimum concentration of it depends on its usual concentration in urine samples and the required precision. The use of $10 \mathrm{~g} \mathrm{~L}^{-1}$ of nitrate as IS was chosen taking into consideration the linear working range for nitrate and one of the requisites of internal standardization by which the IS concentration must be fixed and constant in blanks, standards and samples [25]. The use of high concentration of IS may be an effective strategy to make negligible signal fluctuations that may occur due to variations of analyte in workable samples like human urinary nitrate. Analytical curves in the range of $1-50 \mathrm{~g} \mathrm{~L}^{-1}$ plus $10 \mathrm{~g} \mathrm{~L}^{-1}$ of nitrate was adopted for further studies.

\section{Determination of urea in urine}

After method optimization, five urine samples were analyzed by the IS proposed method. Urea concentrations ranged from 7.6 to $16.8 \mathrm{~g} \mathrm{~L}^{-1}$ (Table I). For comparative purposes, the samples were also analyzed by a reference method based on spectrophotometry. Analysis of Table I reveals that values obtained by both methods are in agreement at $95 \%$ confidence level (paired-t-test). Indeed, it shows that the use of IS improved precision. The relative standard deviations (RSD) associate to the urine sample \#4 analyzed successively $(n=12)$ by the proposed IS method, reference method and conventional external calibration were in the ranges of $1.4-3.9 \%$ (IS), $3.8-6.3 \%$ (Reference method), and $1.8-7.5 \%$ (Conventional external calibration).

Table I. Results $\left(\mathrm{g} \mathrm{L}^{-1}\right)$ of the determination $(n=3)$ of urea in urine samples by the proposed (IS), reference and conventional external calibration methods.

\begin{tabular}{cccc}
\hline Sample & IS & Reference method & $\begin{array}{c}\text { Conventional external } \\
\text { calibration }\end{array}$ \\
\hline $\mathbf{1}$ & $7.6 \pm 0.2$ & $7.9 \pm 0.5$ & $7.3 \pm 0.3$ \\
$\mathbf{2}$ & $16.8 \pm 0.3$ & $18.3 \pm 1.1$ & $16.9 \pm 0.3$ \\
$\mathbf{3}$ & $14.2 \pm 0.2$ & $14.4 \pm 0.8$ & $13.1 \pm 0.4$ \\
$\mathbf{4}$ & $13.0 \pm 0.5$ & $12.5 \pm 0.5$ & $12.8 \pm 0.5$ \\
$\mathbf{5}$ & $12.7 \pm 0.5$ & $13.0 \pm 0.5$ & $13.3 \pm 1.0$ \\
\hline
\end{tabular}

The performance of the proposed method was also evaluated by addition and recovery tests. Recoveries were in the $97-103 \%$ interval (Table II). The application of internal standardization improved the recoveries in comparison with those obtained by conventional external calibration (87 - 108\%). Also, the IS furnished better precision: RSD improved from $1.8-7.5 \%$ (without IS) to $1.4-3.9 \%$ (with IS).

Table II. Recoveries (\%) for $15 \mathrm{~g} \mathrm{~L}^{-1}$ urea added to urine samples determined by the proposed method (IS) and conventional external calibration.

\begin{tabular}{ccc}
\hline Sample & IS & $\begin{array}{c}\text { Conventional external } \\
\text { calibration }\end{array}$ \\
\hline $\mathbf{1}$ & $103 \pm 5$ & $97 \pm 3$ \\
$\mathbf{2}$ & $102 \pm 5$ & $108 \pm 7$ \\
$\mathbf{3}$ & $97 \pm 4$ & $87 \pm 4$ \\
$\mathbf{4}$ & $98 \pm 3$ & $85 \pm 2$ \\
$\mathbf{5}$ & $98 \pm 3$ & $95 \pm 3$ \\
\hline
\end{tabular}




\section{Article}

\section{CONCLUSION}

Nitrate was an IS effective to the direct determination of urea in urine samples by Raman spectroscopy. The proposed method furnished better precision in comparison with the conventional external calibration and reference spectrophotometric method. In general, the proposed IS method here is simple, robust and may be considered environmentally friendly since it provides faster results, minimum sample preparation and lower reagent consumption and minimum waste generated than the reference method.

\section{ACKNOWLEDGMENTS}

The authors thank the Conselho Nacional de Desenvolvimento Científico e Tecnológico - CNPq for financially supporting this work (Project 471453/2013-7) and the fellowship granted to J.A.G.N. (303255/2013-7). São Paulo Research Foundation - FAPESP is also thanks for the fellowship to F.M.F. (2012/23323-7).

Manuscript received Nov. 14, 2017; revised manuscript received Feb. 20, 2018; accepted March 27, 2018

\section{REFERENCES}

1. Francis, P. S.; Lewis, S. W.; Lim, K. F. Trends Anal. Chem., 2002, 21, pp 389-400.

2. Taylor, A. J.; Vadgama, P. Ann. Clin. Biochem., 1992, 29, pp 245-264.

3. Bi, L.; Dong, X.; Yu, Y. J. Lumin., 2014, 153, pp 356-360.

4. Prats-Alfonso, E.; Abad, L.; Casan-Pastor, N.; Gonzalo-Ruiz, J.; Baldrich, E. Biosens. Bioelecton., 2013, 39, pp 163-169.

5. Mitic, S. S.; Miletic, G. Z.; Kostic, D. A.; Rasic. I. D. Chin. J. Chem., 2011, 29, pp 135-142.

6. Koncki, R.; Chudzik, A.; Walcerz, I. J. Pharm. Biomed. Anal., 1999, 21, pp 51-57.

7. Yang, Z.; Zhang, C. Sens. Actuators B, 2013, 188, pp 313-317.

8. Shalini, J.; Sankaran, K. J.; Lee, C.; Tai, N.; Lin, I. Biosens. Bioelectron., 2014, 56, pp 64-70.

9. Alizadeh, T.; Ganjali, M. R.; Rafiei, F. Anal. Chim. Acta, 2017, 974, pp 54-62.

10. Clark, S.; Francis, P. S.; Conlan, X. A.; Barnett, N. W. J. Chromatogr. A, 2007, 1161, pp 207-213.

11. Dou, X.; Yamaguchi, Y.; Yamamoto, H.; Doi, S.; Ozaki, Y. Vib. Spectrosc., 1996, 13, pp 83-89.

12. Heise, H. M.; Voigt, G.; Lampen, P.; Kupper, L.; Rudloff, S.; Werner, G. Appl. Spectrosc., 2001, 55, pp 434-443.

13. Qu, J. Y.; Shao, L. Rev. Sci. Intrum., 2001, 72, pp 2717-2723.

14. Premasiri, W. R.; Clarke, R. H.; Womble, M. E. Lasers Surg. Med., 2001, 28, pp 330-334.

15. Yang, D.; Ying, Y. Appl. Spectrosc. Rev., 2011, 46, pp 539-560.

16. Pelletier, M. J. Appl. Spectrosc., 2003, 57, pp 20a-42a.

17. Oh, C.; Sriphong, L.; Kim, M.; Chung, H.; Asavapichayont, P. J. Raman Spectrosc., 2001, 42, pp 445-451.

18. Yan, X.; Li, P.; Zhou, B.; Tang, X.; Li, X.; Weng, S.; Yang, L.; Liu, J. Anal. Chem., 2017, 89, pp 48754881.

19. Itoh, N.; Bell, S. E. J. Analyst, 2017, 142, pp 994-998.

20. Samek, O.; Obruca, S.; Siler, M.; Sedlacek, P.; Benesova, P.; Kucera, D.; Marova, I.; Jezek, J.; Bernatova, S.; Zemanek, P. Sensors, 2016, 16, pp 1808-1814.

21. Wang, Q.; Sun, Q. Spectrosc. Spect. Anal., 2016, 36, pp 430-435.

22. Zhang, M.; Zhang, X.; Shi, Y.; Liu, Z.; Zhan, J. Talanta, 2016, 158, pp 322-329.

23. Furuya, N.; Matsuyuki, A.; Higuchi, S.; Tanaka, S. Water Res., 1979, 13, pp 371-374.

24. Ferraro, J. R.; Nakamoto, K.; Brown, C. W. Introductory Raman spectrometry. Academic Press, Florida, 2008, $2^{\text {nd }}$ ed., p 434.

25. Raposo Jr., J. L.; Oliveira, A. P.; Jones, B. T.; Neto, J. A. G. Talanta, 2012, 92 , pp 53-57. 